\section{Sky's reflection repels aphids}

Silver spray paint on planting beds could deter some insect and disease problems in vegetable crops, according to UC entomologist Charles Summers. Peppers, melons and squash are extremely susceptible to viruses carried by aphids. The viruses stunt plant growth, reduce yield, and cause deformed, discolored unmarketable fruit.

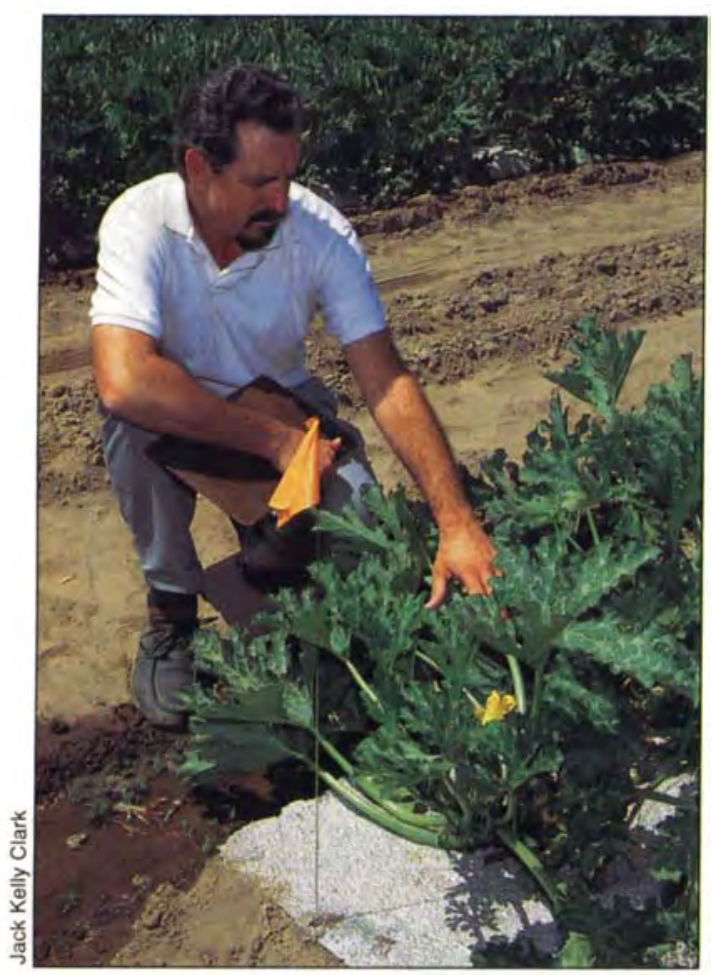

James Stapleton examines zucchini plants for aphids. Silver paint on planting beds deters aphids, which spread harmful plant viruses. acres of zucchini and
“Last year, over 200 yellow crook neck squash in southern Fresno County were disked down without ever a fruit being picked," said Summers.

Because aphids transmit the virus rapidly, insecticides haven't been effective. So scientists are using the silver paint to discourage the pest from landing on the crops. "When an aphid is flying along, looking for a place to land, it cues in on reflections coming off of plant surfaces," Summers explained. "If they see a reflection of the sky, the aphids don't land."

Aluminum foil works, but is far too expensive for commercial production.

In 1993, Summers and IPM advisor and plant pathologist James Stapleton, who are both based at Kearney Agricultural Center, planted zucchini squash, testing eight treatment methods, including the silver spray-on mulch, polyester plastic and beds with no mulch at all. The plants grown on beds treated with spray-on silver mulch produced 3,973 pounds of good quality zucchini per acre. The untreated control beds produced 867 pounds of marketable zucchini per acre. Through all 12 harvests, the scientists reaped the highest marketable yields from the plants treated with spray-on mulch.
"The treatment works," Summers said. "The silver spray mulch repels aphids and delays the onset of virus infection by 10 days to 2 weeks." At the end of the season, $90 \%$ of the fruit on the untreated control plants was virus infected, which would render a commercial harvest pointless. On the silver spray mulch-treated plants, more than $50 \%$ were still marketable so they were able to get three extra harvests.

There are side benefits as well. The plants need less water because the mulches reduce evaporation from the soil surface and the crust formed on the spray-painted surface suppresses weeds.

Silver or white plastic also helps control aphids, but must be gathered and disposed of at the end of the growing season. The water-based paint can simply be disked down and incorporated into the soil with no harmful effects.

\section{Can the ozone layer be restored?}

After studying plasma physics for more than 30 years and the aurora borealis for the last 14 at UCLA's High Power Aurora Stimulation (HIPAS) facility in Alaska, physics professor Alfred Y. Wong thinks the process of ozone layer depletion can be reversed by charging chlorine atoms with an electrical curtain.

In the May issue of Physical Review Letters, Wong outlined supporting evidence from a lab demonstration and computer modeling, which he developed with scientists from Lawrence Livermore Laboratory to test this charging concept. The concept is based on the fact that all reactive atoms such as chlorine, fluorine and bromine need one more electron to complete their outer shells - feeding this "electron affinity" with charges reduces reactivity and ozone-destructive power.

"Chlorine released from chlorofluorocarbons (CFCs) by ultraviolet rays, in excessive amounts due to atmospheric emissions of CFCs, destroys the ozone at a faster rate than it can be created. By charging chlorine atoms, that is by giving them an extra electron, they no longer react with ozone, and the atmospheric levels of ozone can build naturally back to normal levels with no interference from the disabled CFC," Wong said. An advantage, he added, is that the action 
is reversible, in contrast to releasing chemicals that may have undesirable side effects.

In his large ( 3.7 cubic meters) atmospheric chamber at UCLA, Wong created a healthy stratosphere complete with ozone and ultraviolet light. He then injected a minuscule amount of CFC, until nearly all of the ozone was depleted. Then, by charging the model atmosphere with the form of an electrical current generated by a radio frequency transmitter, he disabled the $\mathrm{CFC}$, and the ozone level in the atmosphere returned to normal.

The UCLA physicist has begun testing his idea outside the lab, using helium balloons to lift to the stratosphere a solar-powered platform carrying a large electrical "curtain." Chlorine atoms will be neutralized as they pass through the curtain, gaining an electron.

Wong envisions up to 20 platforms deployed at the North and South poles, which could reduce the ozone hole by $50 \%$ in as little as 5 years. Each platform would cost $\$ 25$ million, but their cost could be offset, for instance, by using them to carry telecommunications and astronomy equipment as well. The platforms would be brought down every 2 to 4 years for maintenance, then reused.

\section{Research}

update

\section{Researchers try to arrest fugitive dust}

$\mathrm{B}$ rown haze, the signature of polluted air, is only the most visible part of the problem. Consider ozone, the invisible toxic gas formed when nitrogen oxides and hydrocarbons react with sunlight, and particulate matter 10 microns $(1 / 7$ the diameter of the average human hair) or less in diameter (PM-10). Both cause health problems and reduce agricultural crop yields.

University of California scientists have previously demonstrated that ozone causes annual losses as high as $20 \%$ in some San Joaquin Valley crops. In current research, they are learning how agriculture both contributes to and mitigates air pollution. Extension air quality specialist David Grantz has found that farm crops remove large amounts of ozone from the air, which may significantly benefit air quality (see page 9).

Other scientists are determining how and to what degree agricultural practices contribute PM-10 dust to the air. PM-10 dust is a health concern because it can bypass the body's natural defense mechanisms and settle permanently in the lungs. (Inhaled dust particles larger than 10 microns in diameter can be expelled.) Once PM-10 settles in the lungs, it can increase asthma attacks, reduce lung function, aggravate bronchitis, result in respiratory disease and lead to premature death, according to Karlyn Black, statewide PM-10 specialist for the California Air Resources Board. PM-10's effects are most apparent in elderly people, children, chronic heart disease patients, chronic respiratory disease patients and people with asthma, but ultimately it affects everyone.

Research defining how best to reduce PM10 is urgently needed. Currently only Lake County meets state PM10 standards. Under the federal Clean Air Act, areas not designated as nonattainment

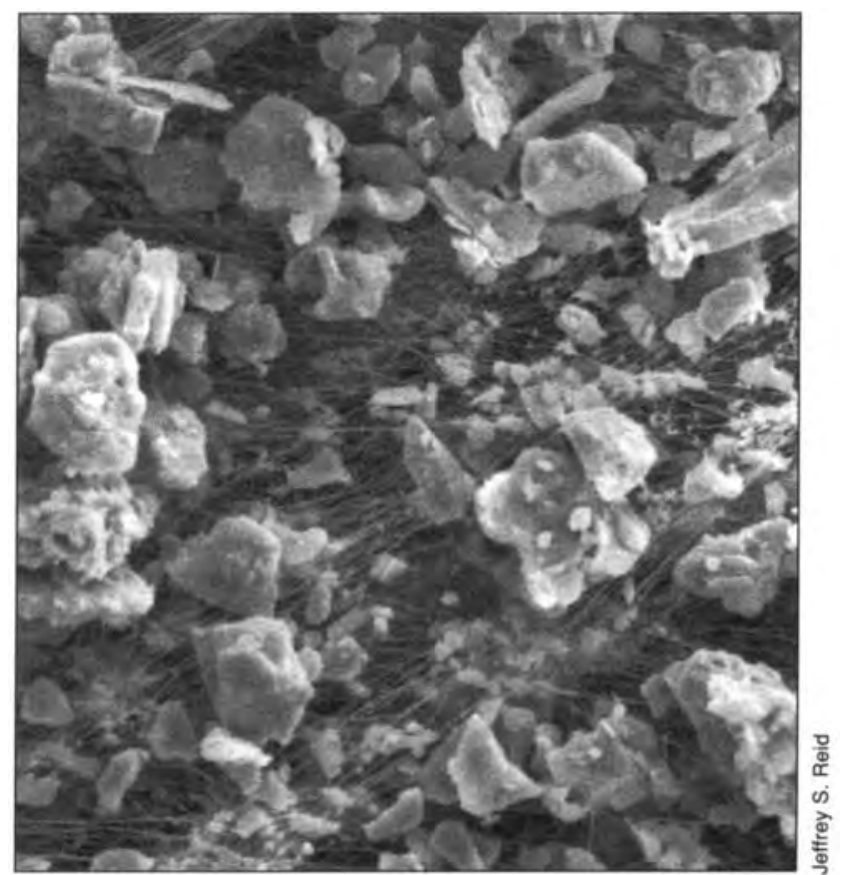

Particulate matter 10 microns or smaller, PM10 , is a health concern because it can settle in the lungs, impairing respiratory functions. 